\title{
Nonlinear dynamics in economic modelling
}

\section{Laura Gardini $^{1}$ - Fabio Lamantia ${ }^{2,3}$ - Davide Radi ${ }^{3,4}$. Ferenc Szidarovszky ${ }^{5}$. Fabio Tramontana ${ }^{6}$}

Accepted: 31 July 2021 / Published online: 18 October 2021

(C) The Author(s), under exclusive licence to Associazione per la Matematica Applicata alle Scienze Economiche e Sociali (AMASES) 2021

This Special Issue on "Nonlinear Dynamics in Economic Modelling" is dedicated to Gian Italo Bischi for his 60th birthday. In order to commemorate the occasion, a number of co-authors and collaborators of Gian Italo, from around the world, gladly agreed to contribute papers to a special issue dedicated to this event. This special issue contains the latest developments in nonlinear economic dynamics, the most active research area Gian Italo has been involved in.

This collection of essays is the outcome of such a process. Most of the authors have been collaborating with Gian Italo throughout his career. We would, first of all, express our gratitude to all contributors, as well as to the referees involved in the editorial process.

Born in 1960 in Urbino, Gian Italo was fascinated by dynamical systems when he was a student of Physics at the University of Bologna thanks to an advanced course on nonlinear phenomena held by professor Giampietro Puppi. Graduated in Physics in 1984, with a thesis on quantitative seismology, Gian Italo started to work for ENI (Italian national society for energy) where he was mainly devoted to the development of numerical computation techniques. In the same period, he collaborated with professor Edoardo Beretta at the University of Urbino, in the field of dynamic models in ecology. In this period, he published some papers on biological applications of nonlinear dynamical systems with delays, represented by functional differential equations, in journals like Mathematical Biosciences or Journal of Mathematical Biology. In 1987, he became a high-school teacher of mathematics and physics, and in 1994 he was appointed as a researcher at the Faculty of Economics of the University of Urbino.

\footnotetext{
$\triangle$ Davide Radi

davide.radi@unipi.it

1 University of Urbino, Urbino, Italy

2 University of Calabria, Rende, Italy

3 VS̆B-Technical University of Ostrava, Ostrava, Czech Republic

4 University of Pisa, via Cosimo Ridolfi 10, 56124 Pisa, Italy

5 Budapesti Corvinus Egyetem, Budapest, Hungary

6 Catholic University of the Sacred Heart, Milan, Italy
} 
Here, he started a long-lasting and prolific research collaboration with Laura Gardini about discrete dynamical systems, in particular those represented by noninvertible maps or maps with vanishing denominators. These research topics, quite innovative and useful in economic applications, have been partly developed in collaboration with professor Christian Mira of Toulouse. New results on the use of critical curves and focal points applied to the study of basins' fractalization, global bifurcations, chaos synchronization and their applications to economics, finance and social sciences, gave rise to several publications both in journals of applied mathematics, ranging from International Journal of Bifurcations and Chaos to Physical Review E , and in journals of economics and social sciences, such as Journal of Economic Behavior and Organization, Journal of Economic Dynamics and Control, Mathematical Social Sciences, Macroeconomic Dynamics, etc. These applications have been favored by fruitful collaborations with economists, such as Mauro Gallegati, Domenico Delli Gatti, Ahmad Naimzada, Giorgio Rodano, Enrico Saltari, Ramon Marimon and others. As a consequence, Gian Italo mastered how to apply his knowledge of dynamical systems to topics ranging from dynamic games with boundedly rational players to nonlinear models of business cycle, as well as macroeconomic models to study monetary and fiscal policies.

At the end of the nineties, he met Michael Kopel and Herbert Dawid with whom he starts working on nonlinear phenomena emerging in dynamic models of industrial organization, evolutionary games and spillover effects in $R \& D$ and innovation diffusion. To testify the commitment and intense scientific production in this field, we mention the Springer Book Nonlinear Oligopolies: Stability and Bifurcations, published in 2010 in collaboration with M. Kopel, C. Chiarella and F. Szidarovszky, that collects the main research results obtained in the field of nonlinear dynamics in oligopoly models by the authors and proposes several applications. In the same years, Gian Italo collaborates with Roberto Dieci and Anna Agliari, as well as his former Ph.D. students: Fabio Lamantia, Lucia Sbragia, Davide Radi and Lorenzo Cerboni Baiardi. With Lamantia and Sbragia, he participated to a national project about dynamic modelling of sustainable fisheries, together with the colleagues Gervasio Antonelli and Elena Viganò of the University of Urbino. In the last decade, Gian Italo's research work focuses on modeling the evolutionary selection of adjustment processes and the related nonlinear phenomena, in collaboration with Fabio Lamantia and Davide Radi, as well as some explorations in behavioral economics with his former student Fabio Tramontana, up to applications of evolutionary games to nonlinear social dynamics in collaboration with Ugo Merlone.

During his career, Gian Italo has also been working to foster a research group that facilitates contacts among young researchers and senior collaborators. Many of these collaborations have resulted in papers collected in special issues and in research volumes co-edited by Gian Italo. Relevant in this direction is also his effort in organizing and promoting periodic conferences. One of these is the biennial meeting Modelli Dinamici in Economia e Finanza (Dynamic Models in Economics and Finance) that takes place at the University of Urbino since 2000; a second relevant appointment is the international conference Nonlinear Economic Dynamics and the related Society that Gian Italo contributed to establish and of which he is currently the president. 
In recent years, he has been involved in an intense activity of popularization and dissemination of mathematics as well as in its interdisciplinary connections with other fields of knowledge, from social sciences to the literature. In this context, we mention his former Ph.D. student Andrea Capozucca, one of the leading Italian experts of science communication and public engagement.

Gian Italo is an active member of the Italian Association for Mathematics Applied to Social and Economic Sciences (AMASES), that he served as a member of the scientific board in the period 2010-2016, and as an Associated Editor of the Journal of the Association (Decisions in Economics and Finance). Due to his activity as science communicator, in 2015 he was invited by the past president of the Association, Achille Basile, to write, in collaboration with the colleagues Angelo Guerraggio and Flavio Pressacco, the history book of the Association's first 40 years: AMASES XL, published by Egea in 2016

This special issue is a way in which Editors and Authors want to celebrate Gian Italo's 60th birthday and thank him for being a source of inspiration, for having contributed in an important way to the spread and development of nonlinear dynamical systems in economics and finance and for the research group that he created in his long career.

Publisher's Note Springer Nature remains neutral with regard to jurisdictional claims in published maps and institutional affiliations. 